\title{
Investigating effects of ball size on the performance of gas lift valve for both modified and optimized seats
}

\author{
Ehsanul Kabir ${ }^{1}$, Hossein Emadi ${ }^{1, *}$, Fathi Elldakli ${ }^{1}$, and Matt Young ${ }^{2}$ \\ 1 TexasTech University, 2500 Broadway, TX 79409, Lubbock - USA \\ ${ }^{2}$ Flowco Solutions, 18511 Imperial Valley Dr., TX 77073, Houston - USA
}

Received: 20 September 2017 / Accepted: 23 January 2018

\begin{abstract}
The seat and the ball are the only two components of a Gas Lift Valve (GLV) that can be switched out to meet changing gas throughput requirements. For this reason, individual pairings of balls and seats must be designed to meet the particular requirements of specific situations. While conventional GLV seats have sharp edges, a modified seat design with partially beveled edges has been shown to improve gas throughput. This design was then tested using benchmark valve and was optimized by beveling the entire port of the seat. These experiments were conducted using a ball diameter that was $0.0016 \mathrm{~m}$ larger than the diameter of the port top, although the effects of even larger ball sizes have also been studied using benchmark valves with conventional seats. Researchers have yet to explore the effects of ball diameters smaller than the Port Top Diameter (PTD) and larger than the Port Bottom Diameter (PBD) for modified and optimized seat designs. In this paper, the effects of smaller ball size on the GLV gas throughput have been analyzed using both modified and optimized seat designs and actual GLV. The ball was $0.0016 \mathrm{~m}$ smaller than the PTD of the seats. Geometric models have been deduced to calculate the generated upstream area (frustum area) open to flow. This frustum area is a function of stem travel, and the dimensions of the seat and ball. Theoretical calculations have been compared with results obtained through robust experimental methods. The entire experimental program was divided into four individual experiments. The static testing was used to fix the dome pressure and the opening pressure. The hysteresis effect associated with the bellows assembly was minimized using the aging procedure. Probe tester was used to measure the stem travel. Finally, the gas throughput of the GLV was measured using dynamic testing. The smaller ball sizes were found to significantly improve the gas throughput of actual GLV. This improvement was as high as $179 \%$ for large PBD seats. However, the frustum area practically decreased for these cases. This result suggests that the flow coefficient has more effect on GLV gas throughput compared to frustum area.
\end{abstract}

\section{Introduction}

Artificial lift covers approximately $96 \%$ of the US oil well market of which roughly $10 \%$ uses gas lift for production (Salinas and $\mathrm{Xu}, 2014$ ). Gas lift is a simple and flexible artificial lift method in which external gas is injected continuously or intermittently from the casing-tubing annulus into the tubing string through specially designed valves (GLV) (Winkler and Blann, 2007). The entire objective is to reduce the flowing bottomhole pressure, thereby increasing the inflow of produced fluids (Lea et al., 2008). Although sophisticated gas lift technologies such as smart GLV (Xu et al., 2013) and advanced Gas-Lift Insert System (GLIS) (Aliyeva and Novruzaliyev, 2015) have been developed, all GLVs are still being manufactured based on King's design (King, 1940). This design consists of

\footnotetext{
* Corresponding author: h.emadibaladehi@ttu.edu
}

a nitrogen-charged dome section and bellows assembly. Benchmark GLV is another type of GLV in which the nitrogen-charged dome and bellows assembly are absent. Laboratory testing is the primary use of this type of GLV. However, Winkler and Camp (1987) successfully used benchmark valve in field applications. The basic components of both types of GLV are shown in Figure 1.

For pressure charging and discharging purposes, a dome seal is present on the top of the GLV. A loading element is attached to the dome section (Brown, 1967). A nitrogencharged bellows assembly is predominantly used as the loading element. However, a spring or a combination of both spring and bellows is also available. The bellows assembly acts very similar to a helical spring and is connected to the stem, which is attached to a ball at its end. Movement of all these sections takes place as a single unit. The ball is seated onto a sized-port when the GLV is closed. In order to prevent the backflow from either the tubing or casing, a check valve is installed on the downstream side of the port. 

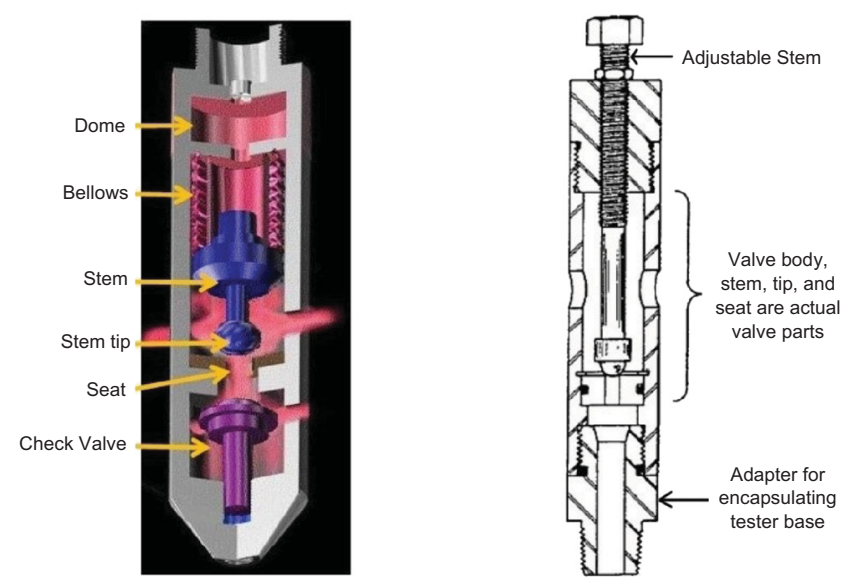

Fig. 1. Basic components of an actual (left) and a benchmark (right) GLV.
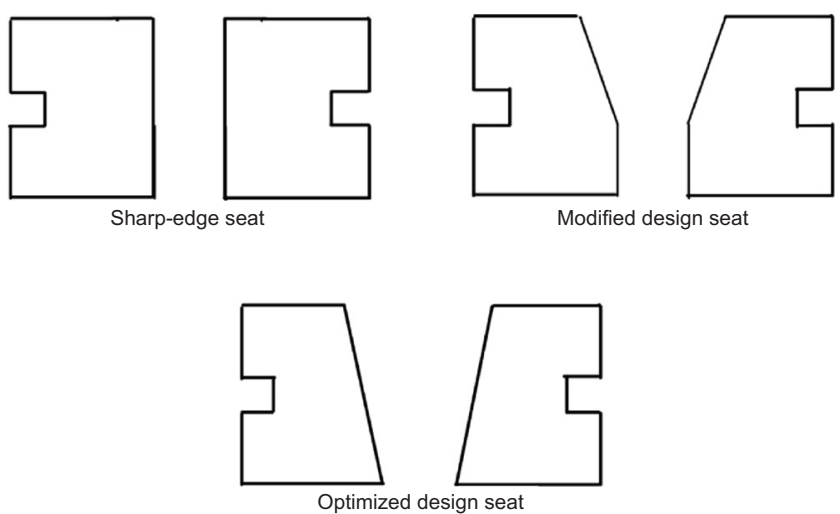

Fig. 2. Three types of seat designs.

Three different types of seat designs are shown in Figure 2. Sharp edge seat design has been the standard practice in the industry for a long time. However, Elldakli et al. (2014b) found out that a beveled seat design (modified design) results in as much as 30\% improvement of gas throughput capacity of the benchmark GLV depending on the beveled angle. The beveled angle is generally measured with respect to the bottom edge of the seat. Based on the results of the beveled seat design, detail CFD simulations were run by Elldakli and Soliman (2017) and the modified seat design was optimized to give the best performance. The optimized design has completely beveled port as opposed to modified design which has partly beveled and partly sharp edge port.

The Injection Pressure Operated (IPO) GLV is primarily controlled by the injection pressure. There are two pressures which cause a valve to open: injection or casing pressure and production or tubing pressure. The injection pressure, operating on the effective bellows area minus the port area, produces the first opening force. The second opening force is produced by the production pressure acting on the valve port area. The closing force mainly comes from the nitrogen-charged dome pressure which acts on the effective bellows area. The stem tip (ball) is

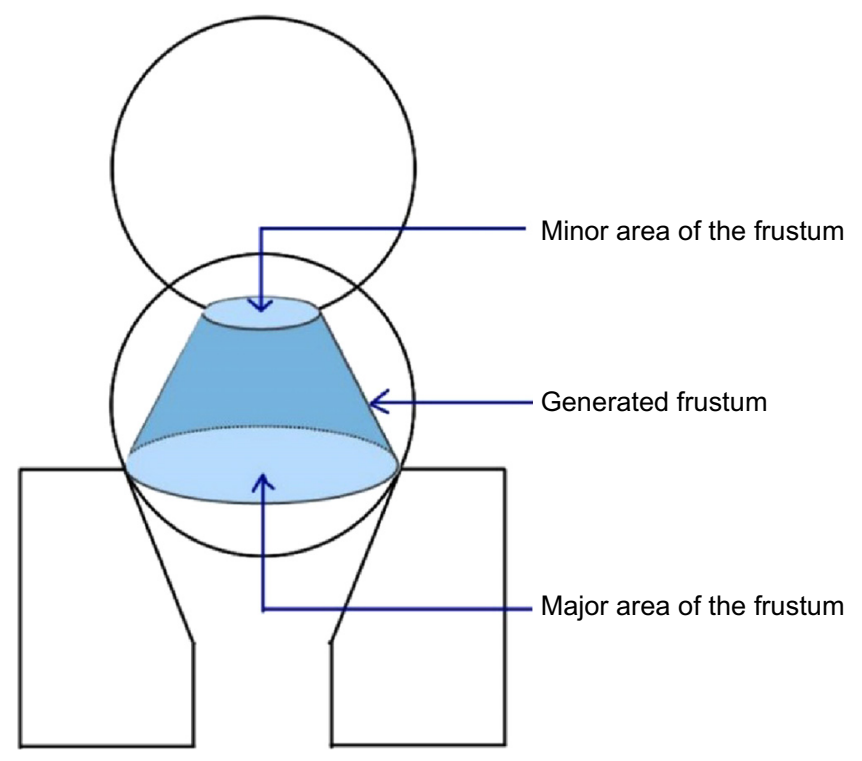

Fig. 3. Generated frustum area for larger ball.

also acted upon by a small fraction of the injection pressure which pushes the stem down. Ball surface area governs this fractional amount of closing force. When the total opening force exceeds the total closing force, the GLV initially begins to open. The opening mechanism is incremental. The difference between the opening and closing forces, and the bellows assembly load rate dictates the stem travel in the actual GLV system.

One of the most important parameters in each GLV is the upstream flowing area. This area is generated by the stem movement away from the seat. A larger upstream flow area is expected to deliver a better gas throughput. The lateral surface area of the frustum of a right circular cone defines the flow area for a partially open valve. This frustum area is generated between the ball surface and the valve seat, and increases as the valve stem moves away from the seat (Fig. 3). The GLV fully opens when the frustum area becomes equal to the port bottom area and provides maximum gas throughput (Winkler and Camp, 1987). Since a GLV is a flow restriction, coefficient of discharge and flow coefficient also affect the gas throughput. However, as indicated in Decker (1993), flow coefficient is the preferred method of quantifying GLV's flow capacity.

In an actual GLV, the bellows assembly performs the most important function by allowing the valve stem tip to move on and off the seat while maintaining the domecharged pressure (Takacs, 2005). When the GLV starts to open (the ball starts to move up), metal bellows connected to the stem begins to get compressed because of axial loading. At some point, the bellows assembly might get completely stacked (Fig. 4). At this point, the ball can no longer move upward, and the frustum area ceases to increase.

\subsection{Effects of ball size}

As recommended by Gas-lift Valve Performance Testing API Recommended Practice 11V2 (Gas-lift Valve Performance Testing API Recommended Practice 11V2, 2001), 


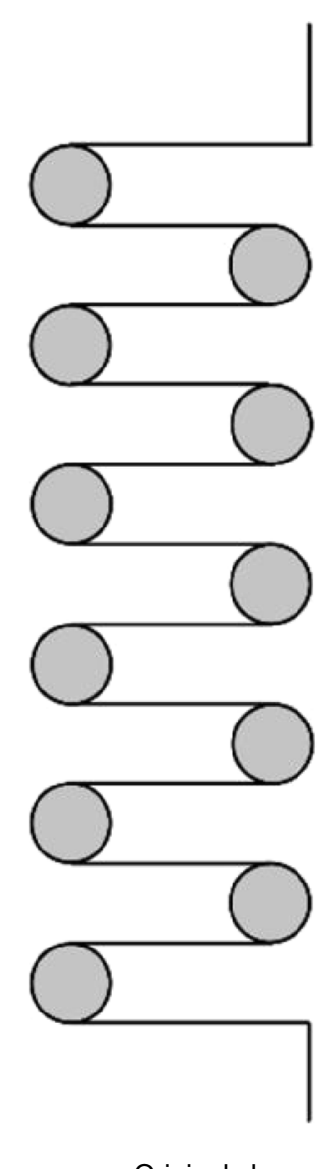

Original shape

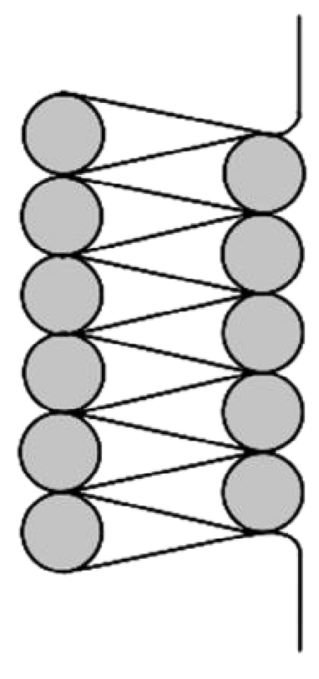

Stacked bellows

Fig. 4. Bellows stacking phenomenon.

the diameter of the ball should be $0.0016 \mathrm{~m}$ larger than the Port Top Diameter (PTD) of the seat. The effects of even larger balls have also been studied by Elldakli et al. (2014a) for benchmark GLV. When the ball is seated on the port top (ball diameter larger than the PTD), the ball/seat contact area, which remains constant, is the major area of the frustum (Fig. 3). The top plane of the frustum is the minor area, which decreases with an increase in stem travel as the ball moves away from the seat. When the ball is seated below the port top (ball diameter smaller than the PTD but larger than the PBD), both the major and the minor frustum areas change with the ball's upward movement (Fig. 5).

The generated frustum area is controlled by three parameters: (i) the major area of the frustum governed by the PTD of the seat, (ii) the minor area of the frustum governed by the ball size and the PTD of the seat, and (iii) the stem travel. Larger balls inherently experience a smaller stem travel compared to smaller balls because of larger size and being seated on top of the seat. However, as shown in Figures 3 and 5, the larger ball might have larger major and minor frustum areas than those of the smaller ball depending on the location of the smaller ball. So, two opposing factors, working at the same time, determine the magnitude of the generated frustum area. Flow coefficient is also expected to have a significant effect on gas

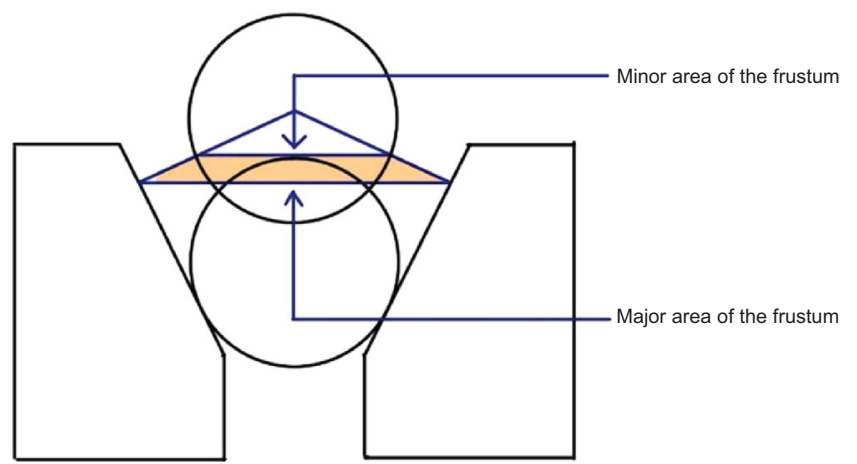

Fig. 5. Generated frustum area for smaller ball.

throughput. The combining effects of the generated frustum area and the flow coefficient of the ball/seat combination determines the overall gas throughput of the GLV.

In this paper, we attempt to investigate the relative effects of these two factors and determine the dominant one. Optimizing the dominant factor will result in a better GLV performance. A set of equations considering the physical parameters of ball and seat has been derived to calculate the frustum area generated for any stem travel both for smaller balls. The calculated frustum areas are then compared against the experimental gas throughput to determine which of the two factors dominantly affects the GLV performance.

\subsection{GLV dynamic performance}

For a long time, GLVs were considered as fixed orifice and the Thornhill-Craver (T-C) equation (Beggs, 1984) was used to calculate the gas flow rate through GLVs. The original T-C equation (Cook and Dotterweich, 1946) was developed for 6-inch bean choke and was not meant to be used for GLVs. A GLV acts as a fixed orifice only when the valve is fully open which rarely happens. Consequently, using the T-C equation would produce erroneous results as indicated by Decker (2008) and Almeida (2011).

One of the first approaches to investigate the orifice nature of the GLV was by Neely et al. (1974). In this study, the GLV was identified as a venturi with variable orifice. This research was further advanced by TUALP (Tulsa University Artificial Lift Project). Several papers related to the modeling of dynamic nature of GLV were published under TUALP between 1992 and 1993. Finally, in 2001, the API Recommended Practice 11V2 (Gas-lift Valve Performance Testing API Recommended Practice 11V2, 2001) was introduced combining the results of TUALP publications to provide a complete method for dynamic testing of GLVs. The API method is not included in this paper to avoid superfluity. A brief description of this method can also be found in Takacs (2005).

In this paper, a pressure decay method, which is also called the "Blowdown test" is used to determine the GLV dynamic performance. The objective of this method is to rapidly measure the flow rate capabilities of the valves under simulated well conditions. As indicated in 


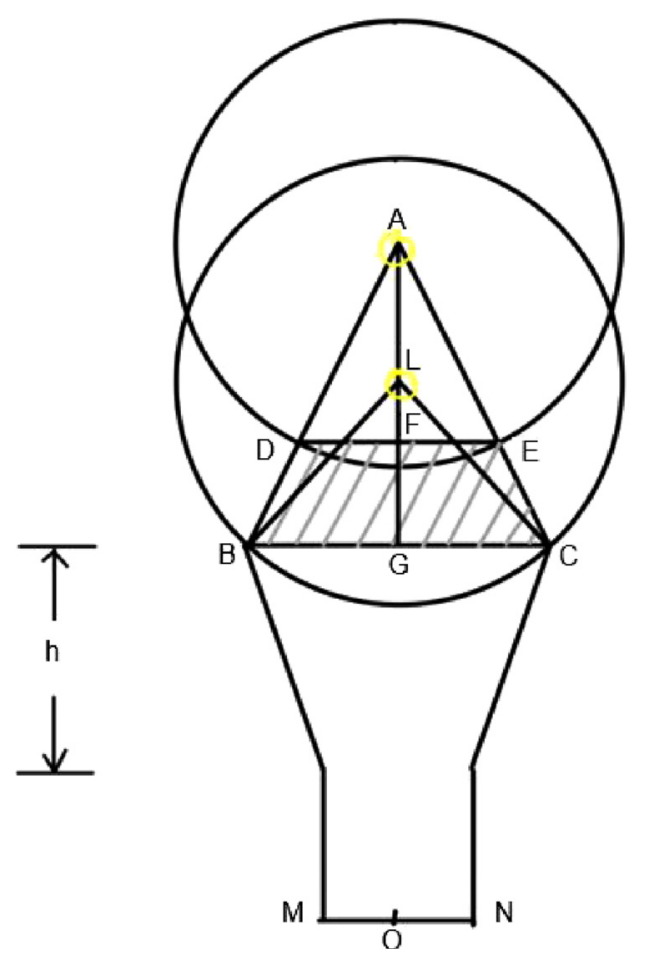

Fig. 6. Ball diameter larger than PTD.

Shahri (2011), this method does not substitute the current method mentioned in the API Recommended Practice 11V2 (Gas-lift Valve Performance Testing API Recommended Practice 11V2, 2001) and is recommended where the flow regime of gas injection is critical or supersonic. The advantage of using blowdown test as the dynamic testing is its rapidity. Since the objective of this work requires significant number of flow tests, the authors chose to use blowdown test. The validity of this method was verified by Shahri and Winkler (2011) and Kulkarni (2005). The detail methodology is explained in Section 2.1.

\subsection{Equations to calculate frustum area as a function of stem travel}

In this section, predictive models to calculate frustum are deduced for two possible cases:

- Case 1: Ball diameter larger than the PTD.

- Case 2: Ball diameter smaller than the PTD.

The models presented here are based on stem travel, and dimensions of the seat and the ball. Geometric principals were used to derive the equations.

\subsubsection{Case 1: Ball diameter larger than PTD}

In this case (Fig. 6), the major area of the frustum is based on the PTD and it remains constant regardless of the stem movement. The minor frustum area changes as the stem moves upward and is dependent on PTD, stem travel, and ball diameter:

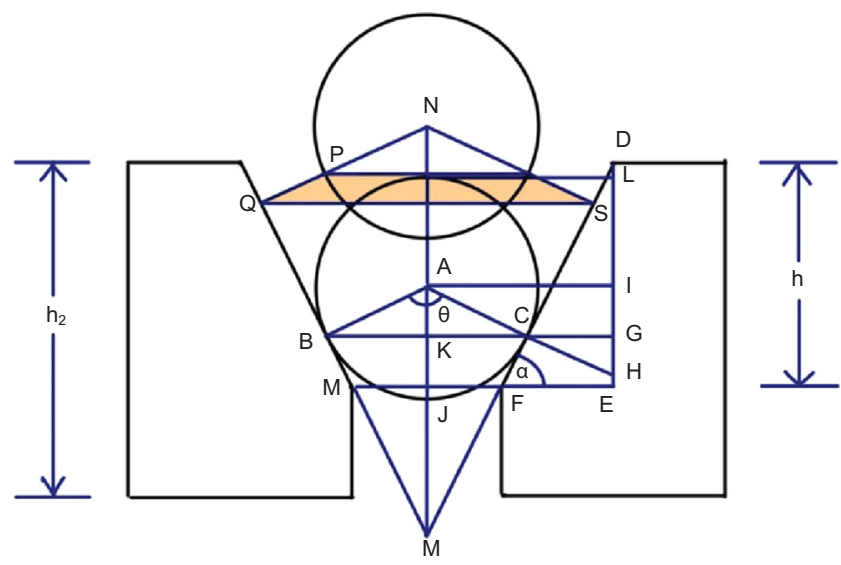

Fig. 7. The perpendicular drawn from the center of the ball to the edge of the seat is inside the seat (smaller ball).

$$
\text { Frustum area }=\frac{\pi z P T D}{2}\left(2-\frac{z}{z+r_{b}}\right) .
$$

In this equation

$$
z=\sqrt{x^{2}+\left(\frac{P T D}{2}\right)^{2}}-r_{b}
$$

and

$$
x=y+\sqrt{r_{b}^{2}-\left(\frac{P T D}{2}\right)^{2}},
$$

here $P T D=$ Port Top Diameter, $\mathrm{m} ; r_{b}=$ ball radius, $\mathrm{m}$; $y=$ linear stem travel, $\mathrm{m}$.

Similar equation to calculate the frustum area was derived by (Elldakli et al., 2014b).

\subsubsection{Case 2: Ball diameter smaller than PTD}

When the ball diameter is smaller than PTD, the ball contacts the seat at a level lower than the top edge of the seat. In this case, there can be two subcases: (i) when the perpendicular drawn from the center of the ball to the edge of the seat is inside the seat (Fig. 7), and (ii) when the perpendicular drawn from the center of the ball to the edge of the seat is outside the seat. For the first subcase, both the major and minor areas of the frustum change as the stem moves. The second subcase is similar to that of the larger ball where the major frustum area is constant and based on the PTD, and the minor frustum area changes with the stem movement.

\subsubsection{First subcase: When the perpendicular drawn from the center of the ball to the edge of the seat is inside the seat (Fig. 7)}

For this subcase, the generated frustum area is a function of PBD, PTD, ball diameter, stem travel, depth of the beveled section of the seat, and the diameter of the contact between 


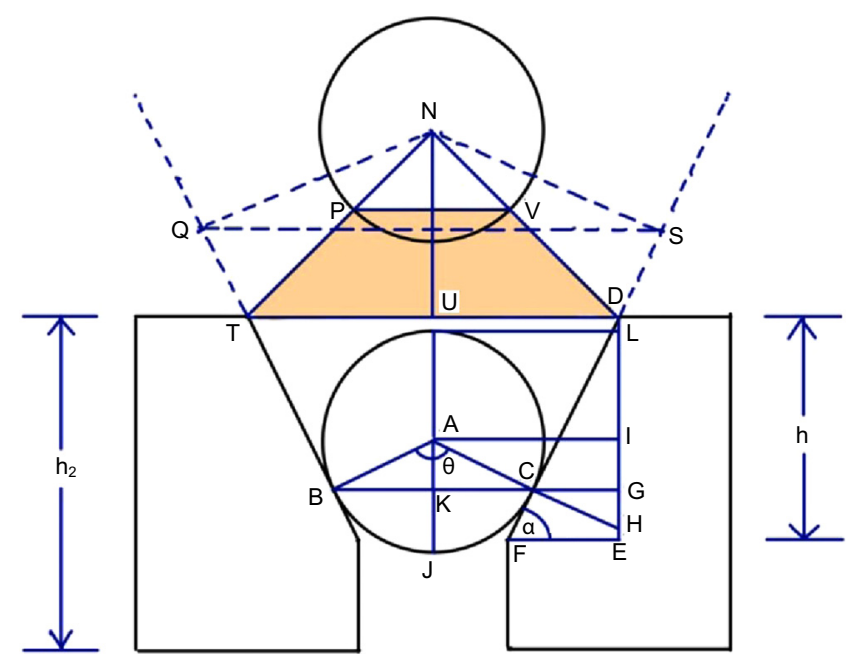

Fig. 8. When the perpendicular drawn from the center of the ball to the edge of the seat is outside the seat (smaller ball).

the ball and the seat $(\mathrm{CCD})$ :

$$
\text { Frustum area }=\frac{y r_{b}}{2 a}\left\{C C D+2 r_{b}\left(1+\frac{y}{a}\right) \sin (b)\right\} .
$$

In this equation

$$
\begin{gathered}
a=r_{b} \cos (b)+e+f \\
b=\tan ^{-1}\left(\frac{2 h}{P T D-P B D}\right), \\
e=\frac{h(C C D-P B D)}{P T D-P B D}
\end{gathered}
$$

and

$$
f=\frac{h \times P B D}{P T D-P B D}
$$

here $y=$ linear stem travel, $\mathrm{m} ; r_{b}=$ ball radius, $\mathrm{m} ; C C D=$ Contact Circle Diameter for smaller balls, $\mathrm{m} ; h=$ depth of the beveled part of the seat, $\mathrm{m} ; P B D=$ Port Bottom Diameter, $\mathrm{m} ; P T D=$ Port Top Diameter, $\mathrm{m}$.

\subsubsection{Second subcase: When the perpendicular drawn from the center of the ball to the edge of the seat is outside the seat (Fig. 8)}

For this subcase, the generated frustum area is a function of PBD, PTD, ball diameter, stem travel, and the diameter of the contact between the ball and the seat $(\mathrm{CCD})$ :

$$
\text { Frustum area }=\frac{j-r_{b}}{2}\left(P T D+r_{b} \frac{P T D}{j}\right) .
$$

In this equation

$$
j=\sqrt{\left(y-\left|g-r_{b} \cos (d)\right|^{2}\right)+\left(\frac{P T D}{2}\right)^{2}},
$$

and

$$
g=\frac{h(P T D-C C D)}{P T D-P B D},
$$

here $r_{b}=$ ball radius, $\mathrm{m} ; P T D=$ Port Top Diameter, $\mathrm{m}$; $y=$ linear stem travel, $\mathrm{m} ; h=$ depth of the beveled part of the seat, $\mathrm{m} ; P B D=$ Port Bottom Diameter, $\mathrm{m} ; C C D=$ Contact Circle Diameter for smaller balls, $m$.

In Section 2, the individual experiments conducted in this study are explained. In Section 3, the cases used in this study are laid out. The plots of probe testing and dynamic testing for selected cases are also presented in this section. In Section 4, the frustum areas calculated using Equations (1), (4), and (9) are compared with the gas throughputs measured using dynamic testing. The trends of frustum area and gas throughput are analyzed in this section. Finally, conclusions are made based on the analyses.

\section{Experimental procedures}

The main aim of the entire experimental program is to test gas lift valve under dynamic conditions by employing "blowdown" or "pressure decay" concept as explained in detail in Kulkarni (2005) and Shahri (2011). The entire program is divided into the following four parts:

1. Static testing

2. Aging

3. Probe testing

4. Dynamic testing (Blowdown)

Parts 1, 2, and 3 are well documented in the API Recommended Practice 11V2 (Gas-lift Valve Performance Testing API Recommended Practice 11V2, 2001). Only the Part 4 (dynamic testing) is described here.

\subsection{Dynamic testing (Blowdown test)}

The methodology behind this technique is simply discharging a certain volume of gas at a certain time until the upstream pressure reaches the final downstream pressure which is ambient pressure. The initial pressure is significantly higher than the test rack opening pressure to ensure a fully open GLV.

The apparatus for this test (Figs. 9 and 10) includes some compartments such as source of high pressure nitrogen gas, upstream and downstream pressure regulators, an extra empty volume with known internal capacity (surge tank), an encapsulated vessel which holds the GLV, the GLV, high-speed pressure transducers, high speed temperature recorder, and a DataAcquisition System (DAQ) which might be integrated with the pressure transducers.

The procedure for running the dynamic testing is as follows:

- the GLV is attached inside the encapsulating vessel and the vessel is closed;

- the upstream pressure is set at a very high value compared to the test rack opening pressure;

- the main feeding valve that is attached to the highpressure nitrogen source is shut-in; 
Table 1. Experimental cases.

\begin{tabular}{|c|c|c|c|c|c|}
\hline Case \# & Seat type & $\begin{array}{l}\text { PBD } \\
\text { (meter) }\end{array}$ & $\begin{array}{l}\text { PTD } \\
\text { (meter) }\end{array}$ & $\begin{array}{l}\text { Ball diameter } \\
\text { (meter) }\end{array}$ & $\begin{array}{l}\text { Ptro } \\
(\mathrm{Pa})\end{array}$ \\
\hline 1 & \multirow{8}{*}{$\begin{array}{l}\text { Modified } \\
\text { design }\end{array}$} & 0.0048 & \multirow{14}{*}{0.0127} & 0.0143 & \multirow{14}{*}{2169752} \\
\hline 2 & & 0.0048 & & 0.0111 & \\
\hline 3 & & 0.0064 & & 0.0143 & \\
\hline 4 & & 0.0064 & & 0.0111 & \\
\hline 5 & & 0.0079 & & 0.0143 & \\
\hline 6 & & 0.0079 & & 0.0111 & \\
\hline 7 & & 0.0095 & & 0.0143 & \\
\hline 8 & & 0.0095 & & 0.0111 & \\
\hline 9 & \multirow{6}{*}{$\begin{array}{l}\text { Optimized } \\
\text { design }\end{array}$} & 0.0064 & & 0.0143 & \\
\hline 10 & & 0.0064 & & 0.0111 & \\
\hline 11 & & 0.0079 & & 0.0143 & \\
\hline 12 & & 0.0079 & & 0.0111 & \\
\hline 13 & & 0.0095 & & 0.0143 & \\
\hline 14 & & 0.0095 & & 0.0111 & \\
\hline
\end{tabular}

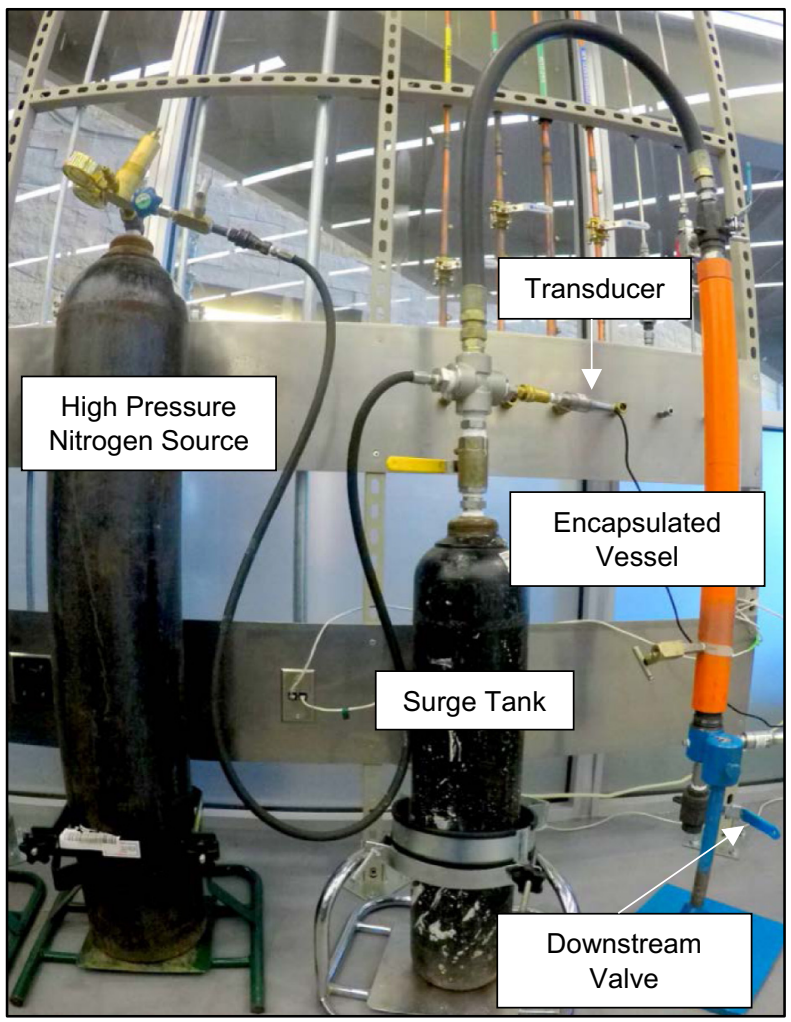

Fig. 9. Actual picture of the blowdown tester.

- wait until the upstream pressure is stabilized;

- the temperature is recorded using a laser temperature gun;

- the pressure and corresponding time recording are started;

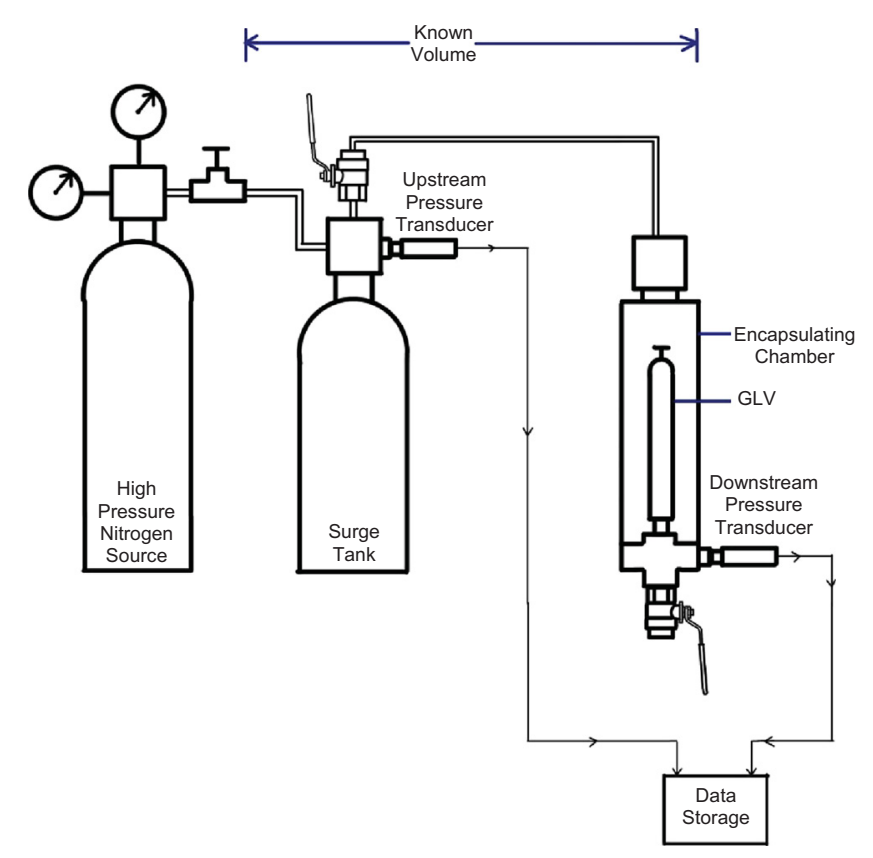

Fig. 10. Schematic of the blowdown tester.

- the downstream valve is kicked open as fast as possible; - the temperature is recorded again using the laser temperature gun.

Temperature is not expected to change much for such a short period of time and for small volume of gas discharged. However, a temperature variation of as small as $\pm 2^{\circ} \mathrm{F}$ was reported to change the flowrate by almost 30\% (Sagar, 1991). That is why temperatures were measured and recorded both immediately before and after discharging the gas. The reason 


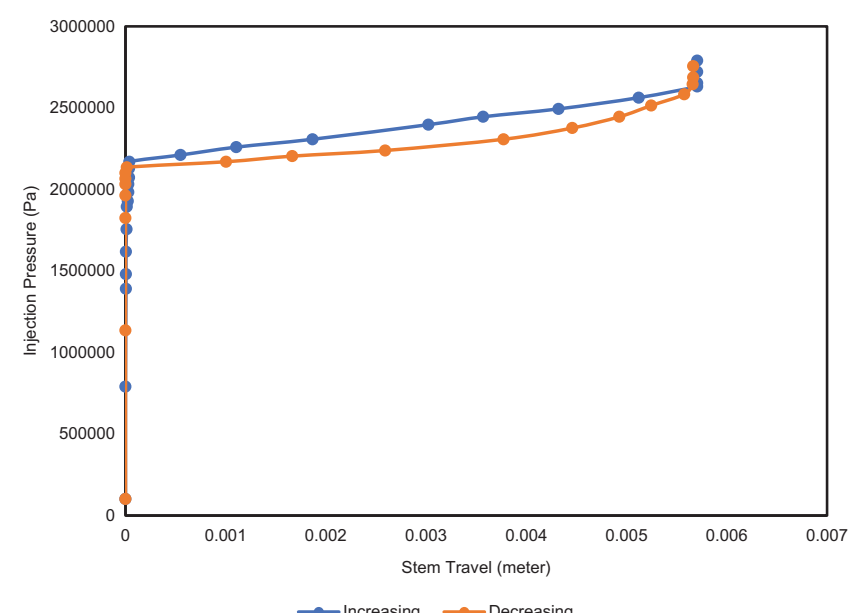

Fig. 11. Probe test (case 3).

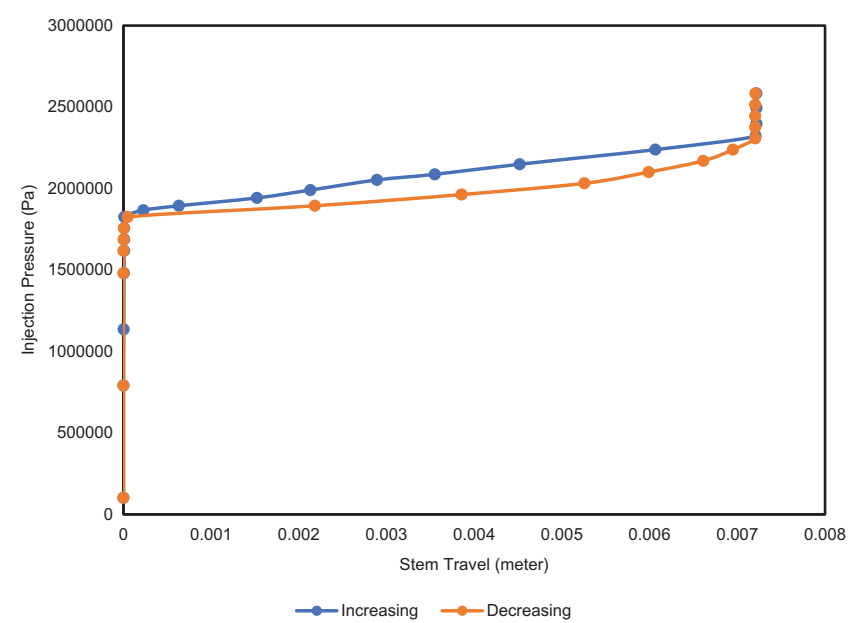

Fig. 12. Probe test (case 9).

for starting data recording before opening the downstream valve is to be able to detect the starting point of pressure decay with time. Once the pressure decay data are recorded, the gas flow rate is calculated using the real gas law. The T-C equation was not used in any part of the calculation because of the reasons mentioned in Section 1.2.

\section{Experimental results}

The fourteen cases mentioned in Table 1 are considered for all the experiments and calculations:

\subsection{Measuring stem travel}

For measuring stem travel, four different modified design seats and three optimized design seats are used with increasing PBD but the same PTD to eliminate the effect of PTD, each with an $0.0016 \mathrm{~m}$ larger and an $0.0016 \mathrm{~m}$ smaller ball. A probe tester is used for this experiment. For the sake of brevity, the results for case 3 and case 9 are presented here (Figs. 11 and 12 respectively).

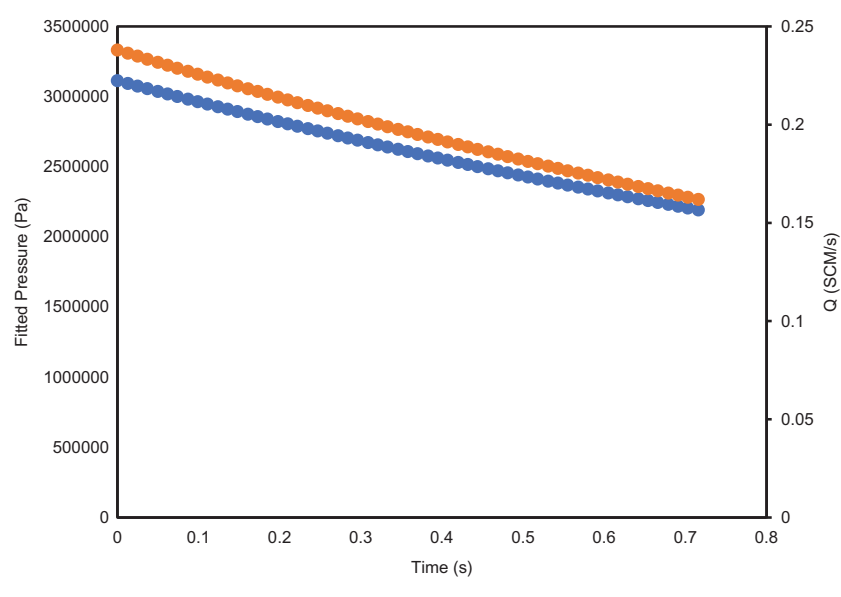

Fig. 13. Blowdown test (case 3).

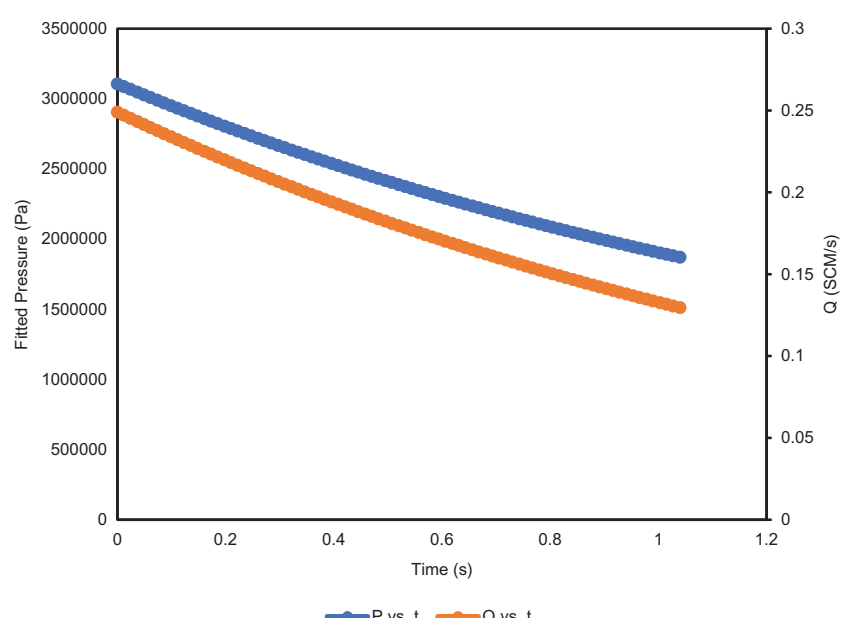

Fig. 14. Blowdown test (case 9).

In these probe test charts, a hysteresis in between increasing and decreasing injection pressure paths is observed in the effective stem travel region. For a particular injection pressure, the stem travel is more for decreasing pressure compared to injection pressure. The reason is - during decreasing pressure, the compressed bellows tries to return to its uncompressed state and by doing so it helps the stem to move even further. As a result, a larger stem travel is observed during decreasing pressure.

Using Equations (1), (4), (9), and the measured stem travel, the corresponding frustum areas are calculated for all fourteen cases.

\subsection{Measuring gas throughput}

The same fourteen cases as in probe tester are used to measure the gas throughput using blowdown tester and pressure decay method. Each blowdown test is repeated two times to eliminate any experimental error. Case 3 and case 9 are presented here (Figs. 13 and 14 respectively). 
Table 2. Comparing change in frustum area with change in gas throughput.

\begin{tabular}{|c|c|c|c|c|c|c|c|c|c|c|}
\hline Case \# & Seat type & $\begin{array}{l}\text { PBD } \\
\text { (meter) }\end{array}$ & $\begin{array}{l}\text { PTD } \\
\text { (meter) }\end{array}$ & $\begin{array}{l}\text { Ball } \\
\text { diameter } \\
\text { (meter) }\end{array}$ & $\begin{array}{l}\text { Stem } \\
\text { travel } \\
\text { (meter) }\end{array}$ & $\begin{array}{l}\text { Frustum } \\
\text { area } \\
\left(\text { meter }^{2}\right)\end{array}$ & $\begin{array}{l}\% \text { Increase } \\
\text { in frustum } \\
\text { area }\end{array}$ & $\begin{array}{l}\% \text { Fully } \\
\text { open }\end{array}$ & $\begin{array}{l}\text { Gas } \\
\text { throughput } \\
\text { (SCM/s) }\end{array}$ & $\begin{array}{l}\% \text { Increase } \\
\text { in gas } \\
\text { throughput }\end{array}$ \\
\hline 1 & \multirow{8}{*}{$\begin{array}{l}\text { Modified } \\
\text { Design }\end{array}$} & 0.0048 & \multirow{14}{*}{0.0127} & 0.0143 & 0.0014 & 2.7993E-05 & \multirow[b]{2}{*}{1} & 157 & 0.1337 & \multirow[b]{2}{*}{4} \\
\hline 2 & & 0.0048 & & 0.0111 & 0.0051 & $2.8380 \mathrm{E}-05$ & & 159 & 0.1386 & \\
\hline 3 & & 0.0064 & & 0.0143 & 0.0013 & $2.6252 \mathrm{E}-05$ & \multirow[b]{2}{*}{7} & 83 & 0.1917 & \multirow[b]{2}{*}{26} \\
\hline 4 & & 0.0064 & & 0.0111 & 0.0056 & $2.8058 \mathrm{E}-05$ & & 89 & 0.2415 & \\
\hline 5 & & 0.0079 & & 0.0143 & 0.0014 & $2.8638 \mathrm{E}-05$ & \multirow[b]{2}{*}{-2} & 58 & 0.2160 & \multirow[b]{2}{*}{5} \\
\hline 6 & & 0.0079 & & 0.0111 & 0.0064 & $2.7929 \mathrm{E}-05$ & & 56 & 0.3769 & \\
\hline 7 & & 0.0095 & & 0.0143 & 0.0014 & $2.8380 \mathrm{E}-05$ & \multirow[b]{2}{*}{-4} & 40 & 0.2140 & \multirow[b]{2}{*}{179} \\
\hline 8 & & 0.0095 & & 0.0111 & 0.0078 & $2.7219 \mathrm{E}-05$ & & 38 & 0.5971 & \\
\hline 9 & \multirow{6}{*}{$\begin{array}{l}\text { Optimized } \\
\text { Design }\end{array}$} & 0.0064 & & 0.0143 & 0.0017 & $3.5024 \mathrm{E}-05$ & \multirow[b]{2}{*}{-17} & 111 & 0.2134 & \multirow[b]{2}{*}{16} \\
\hline 10 & & 0.0064 & & 0.0111 & 0.0070 & $2.9213 \mathrm{E}-05$ & & 92 & 0.2465 & \\
\hline 11 & & 0.0079 & & 0.0143 & 0.0016 & $3.3218 \mathrm{E}-05$ & \multirow[b]{2}{*}{-15} & 67 & 0.2307 & \multirow[b]{2}{*}{54} \\
\hline 12 & & 0.0079 & & 0.0111 & 0.0078 & $2.8187 \mathrm{E}-05$ & & 57 & 0.3549 & \\
\hline 13 & & 0.0095 & & 0.0143 & 0.0017 & $3.3605 \mathrm{E}-05$ & \multirow[b]{2}{*}{-19} & 47 & 0.2402 & \multirow[b]{2}{*}{84} \\
\hline 14 & & 0.0095 & & 0.0111 & 0.0078 & $2.7090 \mathrm{E}-05$ & & 38 & 0.4428 & \\
\hline
\end{tabular}

\section{Result comparison}

The results of all the probe tests and blowdown tests are presented Table 2. In all of these fourteen cases, the observed common trends are:

- For the same PBD and PTD, with increasing ball size, the gas throughput decreases.

- With increasing PBD, the effect of smaller ball size becomes more prominent.

- This effect of smaller ball size is more prominent in the modified design of the seat.

These trends are explained in Sections 4.1 and 4.2.

\subsection{Effect of ball size}

\subsubsection{Case 1 and Case 2 (Fig. 15)}

In cases 1 and 2 , decreasing the ball diameter from $0.0016 \mathrm{~m}$ larger than the PTD to $0.0016 \mathrm{~m}$ smaller than the PTD results in 1\% increase in frustum area and $4 \%$ increase gas throughput. This means for these two cases, flow coefficient is also increasing in addition to the increase in frustum area. The change in gas throughput as a result of changing the ball size is very small because of small port bottom area. The increase in gas flowrate with decreasing ball size can be attributed to the fact that with smaller ball size, comes smaller flow restriction. Also, the fractional injection pressure acting downward on the ball decreases as the ball size decreases. With increasing PBD, this phenomenon is expected to be more noticeable.

\subsubsection{Case 3 and Case 4 (Fig. 16)}

For cases 3 and 4, decreasing the ball diameter from $0.0016 \mathrm{~m}$ larger than the PTD to $0.0016 \mathrm{~m}$ smaller than the PTD results in $7 \%$ increase in frustum area and $21 \%$

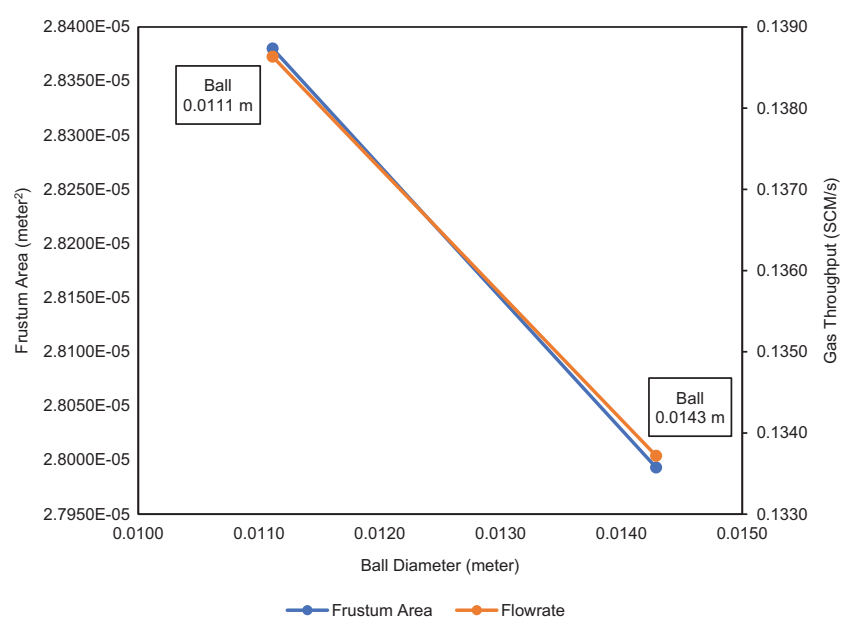

Fig. 15. Effect of ball size (case 1 and case 2).

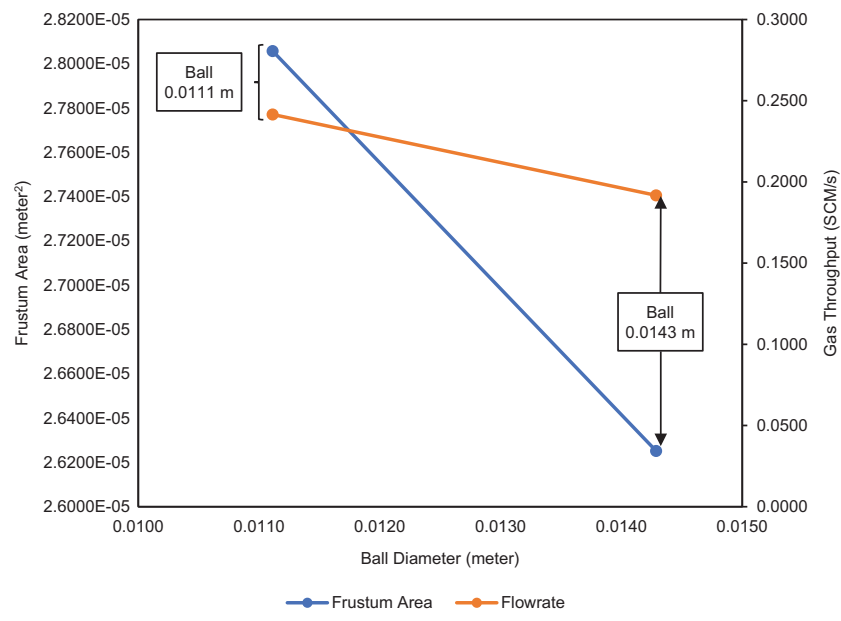

Fig. 16. Effect of ball size (case 3 and case 4$)$. 


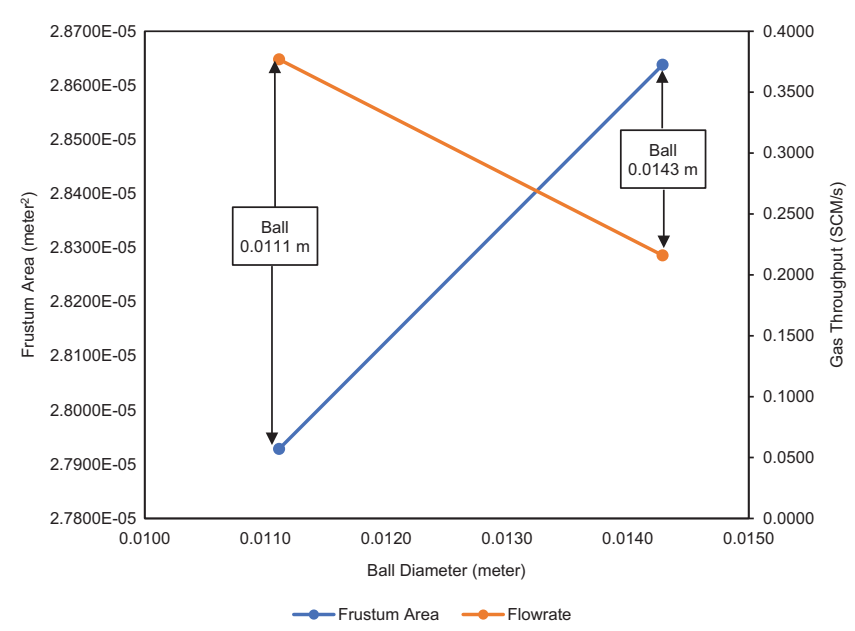

Fig. 17. Effect of ball size (case 5 and case 6 ).

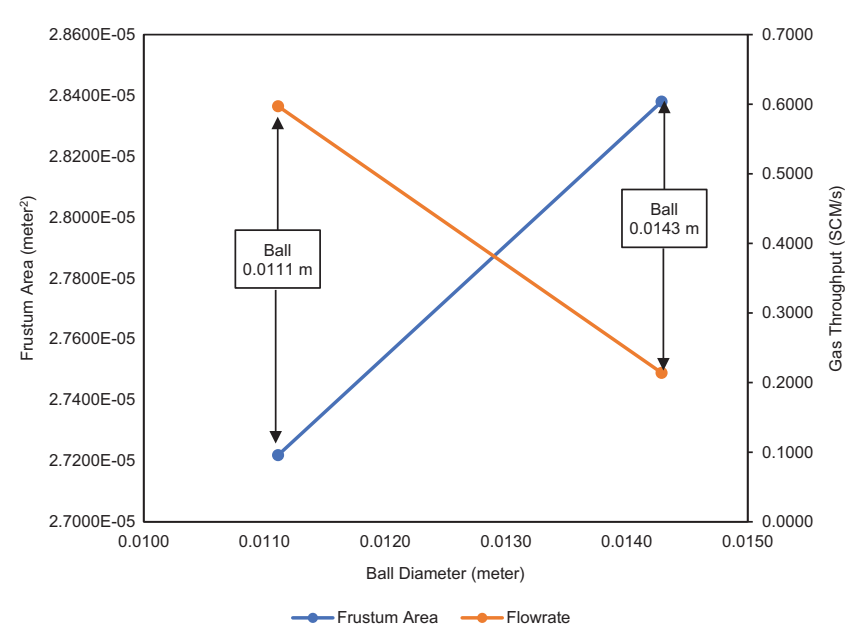

Fig. 18. Effect of ball size (case 7 and case 8).

increase in gas throughput. This means in this case, the flow coefficient is affecting the flowrate more than the frustum area and this effect of flow coefficient is larger than cases 1 and 2. The increase in gas throughput is larger compared to cases 1 and 2. Also, the gas flowrates are significantly higher for both cases 3 and 4 compared to cases 1 and 2. The reason for this is a larger port bottom area. The increase in gas flowrate as a result of decreasing ball size is more evident in these cases. The reasons are explained in Section 4.1.1.

\subsubsection{Case 5 and Case 6 (Fig. 17)}

For cases 5 and 6 , decreasing the ball size decreases the frustum area by $2 \%$ while increases the flowrate by $75 \%$. This means the effect of frustum area on gas throughput is very limited in these two cases. The dominant factor affecting the gas throughput is the flow coefficient and the

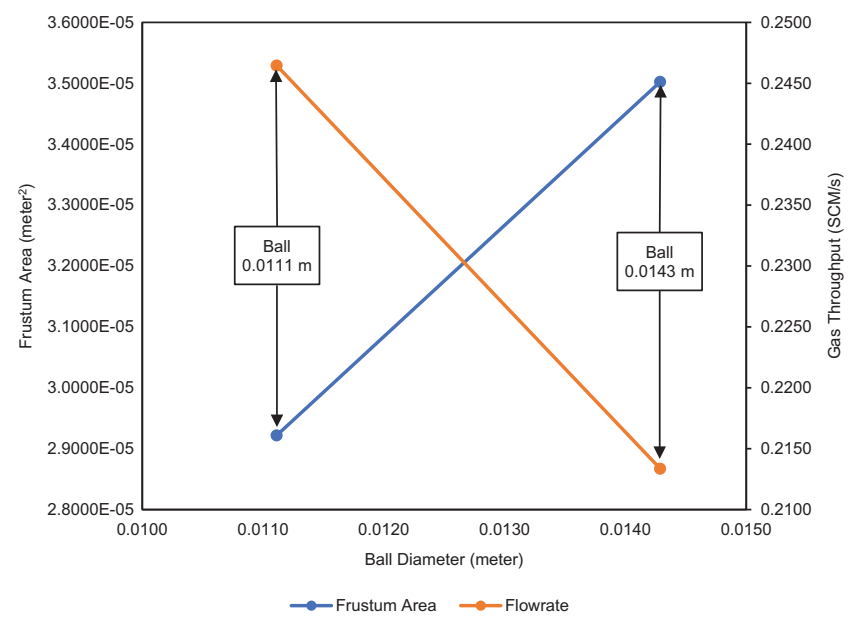

Fig. 19. Effect of ball size (case 9 and case 10).

effect is larger compared to the previous four cases. The increase in gas flowrate is more evident compared to all the precious four cases as well.

\subsubsection{Case 7 and Case 8 (Fig. 18)}

For cases 7 and 8 , decreasing the ball size decreases the frustum area by $4 \%$ while increases the flowrate by $179 \%$. This means the frustum area is affecting the gas throughput to an even smaller extent in these two cases. The dominant factor affecting the gas throughput is the flow coefficient and the effect is larger compared to the previous six cases. The trend of increasing gas flowrate with decreasing ball size is also manifested in these cases. Among all the modified seat design cases, case 7 and case 8 present the largest difference in gas flowrates between smaller and larger ball sizes. This means, with increasing PBD, the effect of ball size becomes more evident.

\subsubsection{Case 9 and Case 10 (Fig. 19)}

Cases 9 and 10 are optimized seats. For these cases, decreasing the ball size decreases the frustum area by $17 \%$ while increases the flowrate by $16 \%$. This means the effect of frustum area is also very small in these two cases. The dominant factor affecting the gas throughput is the flow coefficient. As observed in all the modified seat design cases, the phenomenon of larger gas flowrate with smaller ball size is also evident in these two cases.

\subsubsection{Case 11 and Case 12 (Fig. 20)}

Cases 11 and 12 are optimized seats as well. For these cases, decreasing the ball size decreases the frustum area by $15 \%$ while increases the flowrate by $54 \%$. The effect of frustum area on gas throughput is insignificant. The dominant factor affecting the gas throughput is the flow coefficient and the effect is larger compared to the previous two cases 
Table 3. Effect of port bottom diameter for modified seat design with smaller ball.

\begin{tabular}{lllllllll}
\hline Case \# & $\begin{array}{l}\text { PBD } \\
\text { (meter) }\end{array}$ & $\begin{array}{l}\text { PTD } \\
\text { (meter) })\end{array}$ & $\begin{array}{l}\text { Ball diameter } \\
\text { (meter) }\end{array}$ & $\begin{array}{l}\text { Frustum area } \\
\left(\text { meter }^{2}\right)\end{array}$ & $\begin{array}{l}\text { \% Increase in } \\
\text { frustum area } \\
\text { from prevous case }\end{array}$ & $\begin{array}{l}\text { \% Fully } \\
\text { open }\end{array}$ & $\begin{array}{l}\text { Gas } \\
\text { throughput } \\
\text { (SCM/s) }\end{array}$ & $\begin{array}{l}\text { \% Increase } \\
\text { in gas } \\
\text { throughput }\end{array}$ \\
\hline 2 & 0.0048 & & & $2.8380 \mathrm{E}-05$ & & 159 & 0.1386 & \\
4 & 0.0064 & & & $2.6252 \mathrm{E}-05$ & -8 & 83 & 0.2415 & 74 \\
6 & 0.0079 & 0.0127 & 0.0111 & $2.8638 \mathrm{E}-05$ & 9 & 58 & 0.3769 & 56 \\
8 & 0.0095 & & & $2.8380 \mathrm{E}-05$ & -1 & 40 & 0.5971 & 58 \\
\hline
\end{tabular}

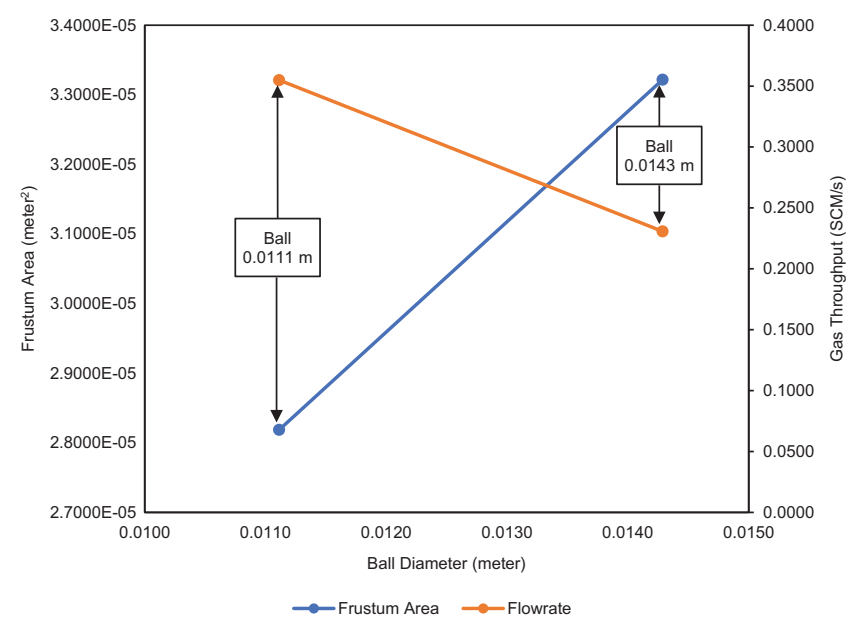

Fig. 20. Effect of ball size (case 11 and case 12).

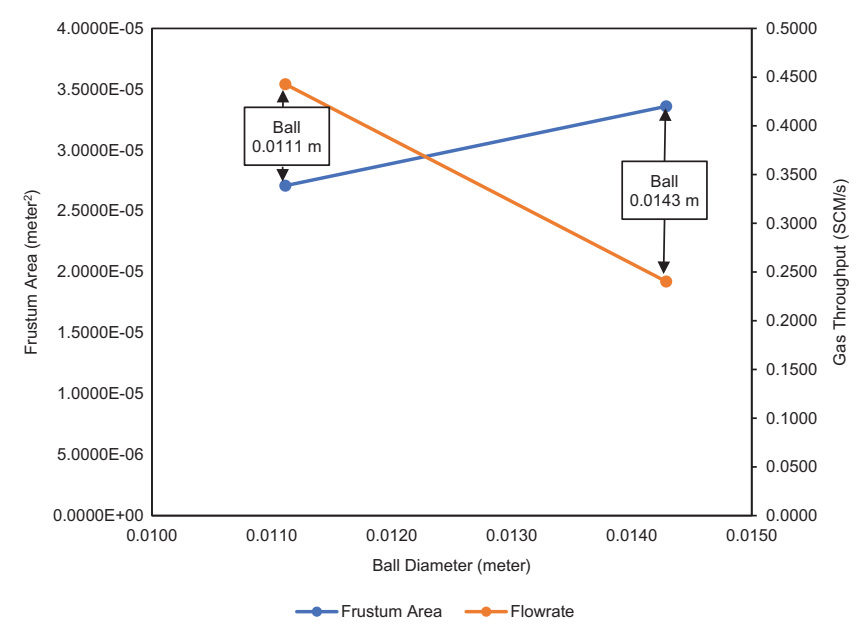

Fig. 21. Effect of ball size (case 13 and case 14).

(case 9 and case 10) of optimized design seats. The phenomenon of higher gas flowrate with smaller ball size is also observed with a larger extent.

\subsubsection{Case 13 and Case 14 (Fig. 21)}

Cases 13 and 14 are also optimized seats. For these cases, decreasing the ball size decreases the frustum area by $19 \%$

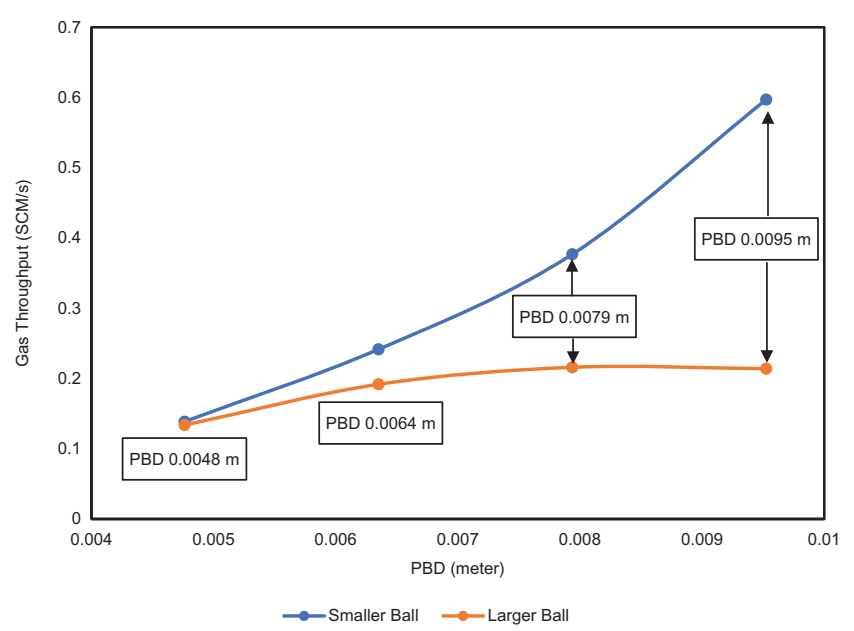

Fig. 22. Effect of port bottom diameter for modified seat design.

while increases the flowrate by $84 \%$. The effect of frustum area on gas throughput is also insignificant. The dominant factor affecting the gas throughput is the flow coefficient and the effect is larger compared to the previous four cases of optimized design seats. Among all the optimized seat design cases, case 13 and case 14 present the largest difference in gas flowrates between smaller and larger ball sizes.

\subsection{Effect of port bottom diameter with respect to ball size}

In this section, the effect of PBD on gas throughput regarding ball size is explained for both modified and optimized seat designs.

Increasing port bottom diameter is expected to result in increasing gas throughput. However, this increase is not in the same proportion for smaller balls and larger balls. As seen in Table 3, Table 4, and Figure 22, the increase in gas throughput becomes less and less significant as PBD increases for the cases where larger balls were used (cases $1,3,5$, and 7$)$. However, for the cases where smaller balls were used (cases 2, 4, 6, and 8), the gas throughput keeps increasing at almost the same percentage with increasing PBD. Similar trend is observed for optimized seat designs as well. This is presented in Table 5, Table 6, and Figure 23. 
Table 4. Effect of port bottom diameter for modified seat design with larger ball.

\begin{tabular}{lllllllll}
\hline Case \# & $\begin{array}{l}\text { PBD } \\
\text { (meter) }\end{array}$ & $\begin{array}{l}\text { PTD } \\
\text { (meter) })\end{array}$ & $\begin{array}{l}\text { Ball diameter } \\
\text { (meter) }\end{array}$ & $\begin{array}{l}\text { Frustum area } \\
\left(\text { meter }^{2}\right)\end{array}$ & $\begin{array}{l}\text { \% Increase in } \\
\text { frustum area } \\
\text { from prevous case }\end{array}$ & $\begin{array}{l}\text { \% Fully } \\
\text { open }\end{array}$ & $\begin{array}{l}\text { Gas } \\
\text { throughput } \\
\text { (SCM/s) }\end{array}$ & $\begin{array}{l}\text { \% Increase } \\
\text { in gas } \\
\text { throughput }\end{array}$ \\
\hline 1 & 0.0048 & & & $2.7993 \mathrm{E}-05$ & & 157 & 0.1337 & \\
3 & 0.0064 & & & $2.8058 \mathrm{E}-05$ & 0 & 89 & 0.1917 & 43 \\
5 & 0.0079 & 0.0127 & 0.0143 & $2.7929 \mathrm{E}-05$ & 0 & 56 & 0.2160 & 13 \\
7 & 0.0095 & & & $2.7219 \mathrm{E}-05$ & -3 & 38 & 0.2140 & -1 \\
\hline
\end{tabular}

Table 5. Effect of port bottom diameter for optimized seat design with smaller ball.

\begin{tabular}{llllllccc}
\hline Case \# & $\begin{array}{l}\text { PBD } \\
\text { (meter) }\end{array}$ & $\begin{array}{l}\text { PTD } \\
\text { (meter) }\end{array}$ & $\begin{array}{l}\text { Ball diameter } \\
\text { (meter) }\end{array}$ & $\begin{array}{l}\text { Frustum area } \\
\left(\text { meter }^{2}\right)\end{array}$ & $\begin{array}{l}\text { \% Increase in } \\
\text { frustum area } \\
\text { from prevous case }\end{array}$ & $\begin{array}{l}\text { \% Fully } \\
\text { open }\end{array}$ & $\begin{array}{l}\text { Gas } \\
\text { throughput } \\
\text { (SCM/s) }\end{array}$ & $\begin{array}{l}\text { \% Increase } \\
\text { in gas } \\
\text { throughput }\end{array}$ \\
\hline 10 & 0.0064 & & 0.0111 & $3.5024 \mathrm{E}-05$ & & 111 & 0.2465 & \\
12 & 0.0079 & 0.0127 & 0.0111 & $3.3218 \mathrm{E}-05$ & 94 & 67 & 0.3549 & 44 \\
14 & 0.0095 & & 0.0111 & $3.3605 \mathrm{E}-05$ & 100 & 47 & 0.4428 & 25 \\
\hline
\end{tabular}

Table 6. Effect of port bottom diameter for optimized seat design with larger ball.

\begin{tabular}{lllllllll}
\hline Case \# & $\begin{array}{l}\text { PBD } \\
\text { (meter) }\end{array}$ & $\begin{array}{l}\text { PTD } \\
\text { (meter) }\end{array}$ & $\begin{array}{l}\text { Ball diameter } \\
\text { (meter) }\end{array}$ & $\begin{array}{l}\text { Frustum area } \\
\left(\text { meter }^{2}\right)\end{array}$ & $\begin{array}{l}\text { \% Increase in } \\
\text { frustum area } \\
\text { from prevous case }\end{array}$ & $\begin{array}{l}\text { \% Fully } \\
\text { open }\end{array}$ & $\begin{array}{l}\text { Gas } \\
\text { throughput } \\
\text { (SCM/s) }\end{array}$ & $\begin{array}{l}\text { \% Increase } \\
\text { in gas } \\
\text { throughput }\end{array}$ \\
\hline 9 & 0.0064 & & 0.0143 & $2.9219 \mathrm{E}-05$ & & 92 & 0.2134 & \\
11 & 0.0079 & 0.0127 & 0.0143 & $2.8187 \mathrm{E}-05$ & -4 & 57 & 0.2307 & 8 \\
13 & 0.0095 & & 0.0143 & $2.7090 \mathrm{E}-05$ & -4 & 38 & 0.2402 & 4 \\
\hline
\end{tabular}

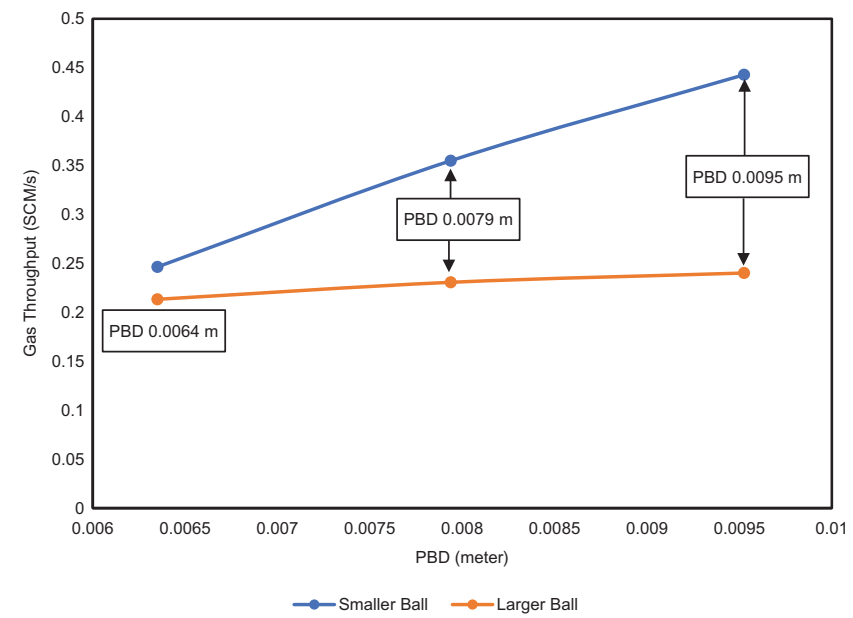

Fig. 23. Effect of port bottom diameter for optimized seat design.

\section{Conclusion}

- A smaller ball performs better than a larger ball for actual GLV regardless of seat types (modified and optimized) and PBD. For the cases when the GLV is not fully open, this effect of smaller ball size is more significant. For 0.0095-meter PBD seat, when the larger ball $(0.0143 \mathrm{~m})$ was replaced by the smaller ball $(0.0111 \mathrm{~m})$, the increase in gas throughput was found to be as high as $179 \%$.

- The two factors affecting the GLV gas throughput are frustum area and flow coefficient. Flow coefficient is mainly affected by the shape of the flow path and flow restriction. Since smaller balls create less restriction to the flow, both flow coefficient and gas flow rate through GLV increase.

- For larger PBD seats where the GLV is not fully open, the flow coefficient was found to be the prime factor affecting gas throughput. In these cases, a smaller ball size provided a higher flow rate despite having a smaller frustum area owing to less flow restriction. When the ball diameter was decreased from $0.0143 \mathrm{~m}$ to $0.0111 \mathrm{~m}$ for 0.0079 -meter PBD seat, the gas flow rate through GLV increased by $75 \%$ despite the frustum area decreased by $2 \%$.

\section{Nomenclature}

GLV Gas Lift Valve

y linear stem travel, $\mathrm{m}$

$r_{b} \quad$ ball radius, $m$ 
PTD Port Top Diameter, $\mathrm{m}$

$P B D$ Port Bottom Diameter, $\mathrm{m}$

$C C D$ Contact Circle Diameter for smaller balls, $\mathrm{m}$

$h \quad$ depth of the beveled part of the seat, $m$

$h_{2} \quad$ seat height, $\mathrm{m}$

$\theta$ central angle created at the center of the ball, degrees

$\alpha \quad$ angle of the beveled edge of the seat with respect to horizontal, degrees

$P_{\text {tro }} \quad$ test rack opening pressure, $\mathrm{Pa}$

$P_{v c} \quad$ valve closing pressure, $\mathrm{Pa}$

$C_{t} \quad$ nitrogen temperature correction factor, dimensionless

$A_{p} \quad$ port area, $\mathrm{m}^{2}$

$A_{b} \quad$ effective bellows area, $\mathrm{m}^{2}$

$\Delta \quad$ frustum area, $\mathrm{m}^{2}$

$Q \quad$ gas flowrate, Standard Cubic Meter/second (SCM/s)

\section{References}

Aliyeva F., Novruzaliyev B. (2015) Gas lift - fast and furious, SPE Annual Caspian Technical Conference \& Exhibition, Baku, Azerbaijan, SPE-177359-MS. DOI:10.2118/177359-MS.

Almeida A. (2011) A model to calculate the theoretical critical flow rate through venturi gas lift valves (includes Addendum), SPE J., 16, 01, 134-147. DOI:10.2118/126184-PA.

Beggs H. (1984) Gas Production Operations, Tulsa, Gulf Pub Co. Brown K. (1967) Gas Lift: Theory and Practice, Prentice-Hall.

Cook H., Dotterweich F. (1946) Report on the Calibration of Positive Flow Beans as Manufactured by Thornhill-Craver Company, Houston, Texas, USA, Department of Engineering, Texas College of Arts and Industries.

Decker K. (1993) Gas-lift valve performance testing, Oklahoma City, Society of Petroleum Engineers. DOI:10.2118/25444-MS.

Decker K. (2008) IPO gas lift design with valve performance, SPE Prod. Oper., 23, 04, 464-467. DOI:10.2118/109694-PA.

Elldakli F., Soliman M. (2017) Optimum design for new gas lift valve seat, J. Petrol. Sci. Eng., 149, 456-464. Retrieved from http://www.sciencedirect.com/science/article/pii/ S0920410516308804.

Elldakli F., Soliman M., Shahri M. (2014a) Enhanced Gas Lift Valve Performance for Sharp Edged Seat using Larger Ball Sizes, Southwestern Petroleum Short Course.
Elldakli F., Soliman M., Shahri M., Winkler H., Gamadi T. (2014b) Improved gas lift valve performance using a modified design for GLV seat, Artificial Lift Conference North America, Houston, Society of Petroleum Engineers. DOI:10.2118/171342-MS.

Gas-lift Valve Performance Testing API Recommended Practice 11V2. (2001) API Recommended Practice 11V2, 2, American Petroleum Institute.

King W. (1940) United States of America Patent No. 2,339,48\%.

Kulkarni R. (2005) Modeling of gas lift valve performance by regressing model parameters to rapidly obtain blowdown data, M.S. Thesis, Texas Tech University, Bob L. Herd Department of Petroleum Engineering, Lubbock.

Lea J., Nickens H., Wells M. (2008) Gas lift, in: Gas Well Deliquification (2 ed.), Gulf Professional Publishing, p. 333.

Neely A., Montgomery J., Vogel J. (1974) A field test and analytical study of intermittent gas lift, Soc. Petrol. Eng. J., 14, 05, 502-512. DOI:10.2118/4538-PA.

Sagar R. (1991) Improved dynamic model of gas-lift valve performance, Master of Science Thesis, University of Tulsa, Tulsa.

Salinas B., Xu Z. (2014) Optimizing gas lift operations using disintegrable gas lift valve plugs, SPE Artificial Lift Conferene E) Exhibition-North America, Houston, SPE-171374-MS. DOI:10.2118/171374-MS.

Shahri M. (2011) Simplified and rapid method for determining flow characteristics of every gas-lift valve (GLV), Ph.D. Dissertation, Texas Tech University, Bob L. Herd Department of Petroleum Engineering, Lubbock.

Shahri M., Winkler H. (2011) Practical method for measurement of injection-gas throughput of each, SPE Production and Operations Symposium, Oklahoma City, SPE-141055-MS.

Takacs G. (2005) Gas lift valves, in: Gas Lift Manual, PennWell Corp, p. 182.

Winkler H., Blann J. (2007) Gas lift, in: Clegg J.D. (ed.), Petroleum Engineering Handbook (Vol. 4), Society of Petroleum Engineers, p. 521.

Winkler H., Camp G. (1987) Dynamic performance testing of single-element unbalanced gas-lift valves, USA, SPE-14348PA. DOI:10.2118/14348-PA.

Xu Z., Richard B., Kritzler J. (2013) Smart gas lift valves enhance operation efficiency of offshore wells, SPE Annual Technical Conference and Exhibition, New Orleans, SPE-166291-MS. DOI:10.2118/166291-MS. 